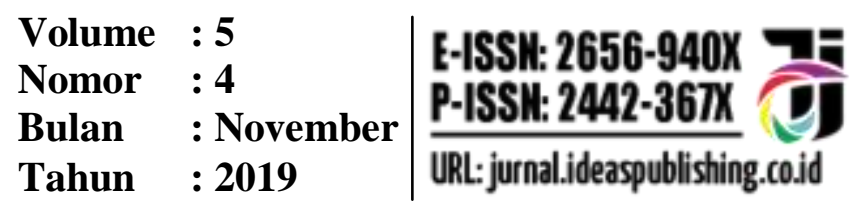

\title{
Strategi Perencanaan Supervisi Akademik Kepala Madrasah
}

\author{
Heriyanto Dalanggo \\ Kemenag Kabupaten Pohuwato Provinsi Gorontalo \\ surel: herianto.dalanggo81@ gmail.com
}

DOI: 10.32884/ideas.v5i4.226

\begin{abstract}
Abstrak
Salah satu tugas kepala madrasah/sekolah adalah melaksanakan supervisi akademik. Strategi pelaksanaan yang tepat sangat dibutuhkan agar pelaksanaan supervisi akademik berjalan efektif. Kegiatan supervisi akademik oleh kepala madrasah/sekolah disamping menguasai konsep, juga dapat menguasai prinsip-prinsip, dimensi-dimensi, fungsi- fungsi dan kompetensi rencana program supervisi akademik. Strategi lainnya bahwa seorang kepala madrasah/sekolah semestinya menguasai prinsip-prinsip dalam mensupervisi, teknik-teknik supervisi, untuk meningkatkan kompetensi kepala madrasah/sekolah sebagai supervisior.
\end{abstract}

Kata kunci: strategi perencanaan, supervisi akademik, kepala madrasah

\section{Pendahuluan}

Salah satu tugas kepala sekolah adalah melaksanakan supervisi akademik. Beberapa keterampilan yakni konseptual, interpersonal, dan teknikal diperlukan untuk melaksanakan supervisi akademik secara efektif (Glickman et al., 2007). Oleh karena itu, setiap kepala sekolah dituntut memiliki dan menguasai konsep supervisi akademik, yakni pengertian, tujuan dan fungsi, prinsip-prinsip, dan dimensi-dimensi substansi supervisi akademik. Supervisi atau pengawasan merupakan salah satu fungsi administrasi pendidikan yang bertujuan untuk menjaga dan mendorong agar pelaksanaan kegiatan belajar mengajar di sekolah dapat berjalan lancar, berhasil guna, dan tepat guna sesuai dengan peraturan perundang-undangan yang berlaku. Supervisi ini merupakan suatu kegiatan pengawasan profesional yang menitikberatkan pada beberapa prinsip supervisi yang seharusnya sudah dikuasai oleh seorang kepala sekolah sehingga pelaksanaan supervisi tidak menyimpang dari ketentuan yang telah ada. Dengan kata lain, seorang kepala sekolah wajib menguasai konsep dasar supervisi, teknik-teknik supervise, hingga pada penilaian dan perbaikan bagi guru dengan benar. Hal ini dikarenakan hakikat supervisi yaitu membantu guru meningkatkan kompetensinya.

Supervisi yang dilakukan oleh kepala sekolah adalah supervisi secara langsung, mengingat waktu yang sangat banyak yang dimiliki kepala sekolah untuk bisa bertatap

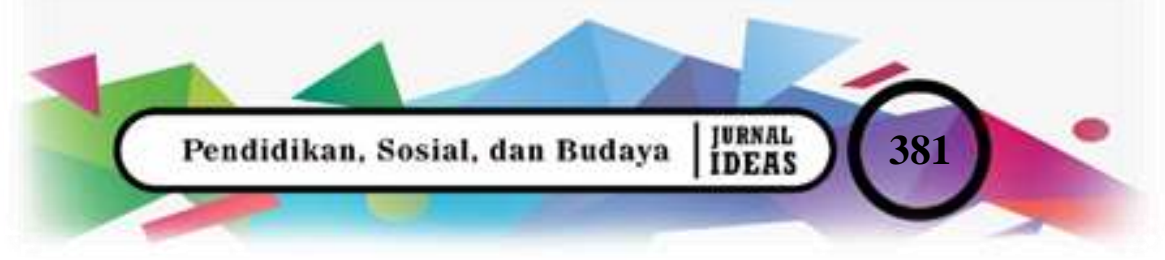




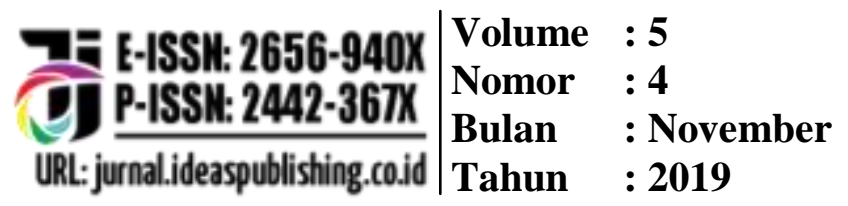

muka dengan dewan guru. Jika peranan kepala sekolah sebagai supervisor dapat berjalan dengan baik, maka mutu sekolah akan menjadi baik. Supervisi akademik merupakan supervisi yang berfokus pada pengamatan masalah akademik. Masalah akademik tersebut mencakup berbagai hal dalam lingkup kegiatan pembelajaran yang dilaksanakan oleh guru dalam membantu proses belajar peserta didik. Supervisi akademik dilakukan untuk mengetahui bagaimana proses pembelajaran yang berlangsung di kelas. Dengan demikian, tulisan ini di fokuskan pada strategi perencanaan supervisi akademik kepala madrasah/sekolah, melalui a) konsep supervisi akademik, dan b) perencanaan program supervisi akademik.

\section{Pembahasan}

Strategi perencanaan supervisi akademik kepala madrasah/sekolah dapat dilaksanakan melalui implementasi dan pengembangan: a) konsep supervisi akademik dan b) perencanaan program supervisi akademik.

\section{Konsep Supervisi Akademik}

Suatu usaha untuk memperbaiki dan meningkatkan proses pembelajaran yang dilakukan oleh guru, kepala madrasah/sekolah bertugas menyelenggarakan serta melaksanakan kegiatan supervisi. Tugas ini terbilang penting karena melalui peran supervisor, kepala madrasah/sekolah mampu memberi bantuan, bimbingan, ataupun layanan kepada guru dalam tugasnya ataupun dalam memecahkan berbagai masalah yang dihadapi saat proses pembelajaran. Salah satu upaya untuk meningkatkan profesional guru adalah melalui supervisi. Menurut Suraiya dkk., (2016) bahwa supervisi pendidikan merupakan bantuan untuk meningkatkan profesional guru melalui pembahasan secara berdua atau kelompok tentang kajian masalah pendidikan dan pengembangan untuk menemukan solusi atas berbagai alternatif pengembangan untuk meningkatkan profesional.

Adapun supervisi akademik yang dilaksanakan kepala sekolah adalah (1) memahami konsep, prinsip, teori dasar, karakteristik, serta kecenderungan perkembangan setiap bidang pengembangan pembelajaran kreatif, inovatif, pemecahan masalah, berpikir kritis, dan naluri kewirausahaan, (2) memberikan pembimbingan bagi guru dalam 


\section{Volume : 5 \\ Nomor : 4 \\ Bulan : November \\ Tahun : 2019

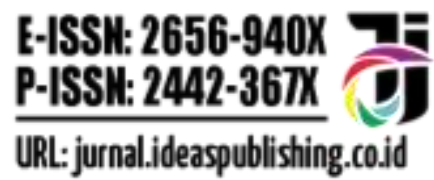

penyusunan silabus tiap bidang pengembangan di sekolah atau mata pelajaran di sekolah yang berdasarkan standar isi, standar kompetensi dan kompetensi dasar, dan prinsipprinsip pengembangan KTSP, (3) memberikan bimbingan bagi guru dalam memilih dan menerapkan strategi/ metode/teknik pembelajaran/bimbingan yang berguna untuk mengembangkan potensi siswa, (4) memberikan pembimbingan bagi guru dalam melaksanakan kegiatan pembelajaran/bimbingan (di kelas, laboratorium, dan/atau di lapangan) guna mengembangkan potensi siswa, (5) memberikan bimbingan bagi guru terkait pengelolaan, perawatan, pengembangan, dan penggunaan media pendidikan dan fasilitas pembelajaran, serta (6) memberi motivasi untuk guru agar memanfaatkan teknologi informasi dalam pembelajaran.

Prinsip utama kompetensi supervisi akademik adalah membina guru untuk meningkatkan mutu proses pembelajaran. Sasaran supervisi akademik adalah guru dalam melakukan tugasnya pada proses pembelajaran. Tugas tersebut meliputi penyusunan materi ajar, penyusunan silabus dan RPP, pemilihan strategi/metode/teknik pembelajaran, penggunaan media dan teknologi informasi dalam pembelajaran, penilaian proses dan hasil pembelajaran, serta melakukan penelitian tindakan kelas. Oleh karena itu, materi ini diharapkan mampu menambah wawasan kepala sekolah dalam meningkatkan kompetensi supervisi akademik yang mencakup: (1) pemahaman konsep supervisi akademik, (2) penyusunan rencana program supervisi akademik, (3) penerapan berbagai teknik supervisi akademik, (4) penerapan supervisi klinis, dan (5) pelaksanaan tindak lanjut supervisi akademik.

Berdasarkan teorinya, maka supervisi dapat dimaknai melalui pengertian, tujuan, prinsip-prinsip, dan dimensi-dimensi secara konseptual dalam kegiatan akademik.

\section{Pengertian Supervisi Akademik}

Supervisi akademik merupakan serangkaian kegiatan yang bertujuan untuk membantu guru mengembangkan kemampuannya dalam pengelolaan proses pembelajaran untuk mencapai tujuan pembelajaran (Daresh, 1989, Glickman, et al., 2007). Supervisi akademik sangat erat kaitannya dengan penilaian kinerja guru dalam mengelola pembelajaran. 


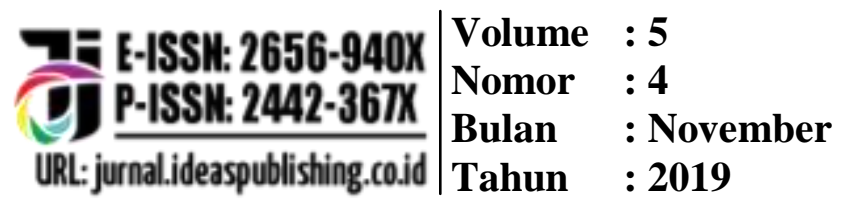

Sergiovanni (1987) menegaskan bahwa refleksi praktis penilaian kinerja guru dalam supervisi akademik merupakan pengamatan kondisi nyata kinerja guru untuk mencari tahu berbagai hal. Misalnya kegiatan yang dilaksanakan oleh guru dan siswa di kelas, kegiatan atau aktivitas-aktivitas yang bermakna bagi guru dan murid, upaya yang dilakukan oleh guru dalam mencapai tujuan akademik, serta kelebihan dan kekurangan guru dalam mencari cara untuk mengembangkannya. Beberapa poin pengamatan ini akan menghasilkan informasi mengenai kemampuan pengelolaan pembelajaran oleh guru. Hal yang perlu ditegaskan adalah selesainya penilaian kinerja bukan berarti pelaksanaan supervisi akademik sudah berakhir. Proses tersebut harus diikuti dengan tindak lanjut yakni perancangan program supervisi akademik hingga implementasi program tersebut dengan maksimal.

\section{Tujuan dan Fungsi Supervisi Akademik}

Tujuan supervisi akademik meliputi: (1) membantu guru mengembangkan kompetensi profesionalnya, (2) mengembangkan kurikulum, (3) mengembangkan kelompok kerja guru, serta memberi pembimbingan terkait penelitian tindakan kelas (PTK) (Glickman et al., 2007; Sergiovanni, 1987).

\section{Prinsip-Prinsip Supervisi Akademik}

Beberapa prinsip supervisi akademik mencakup: (1) praktis, atau mudah diimplementasikan sesuai kondisi sekolah, (2) sistematis, yaitu dikembangkan sesuai perencanaan program supervisi yang matang dan tujuan pembelajaran, (3) objektif, atau masukan berdasarkan berbagai aspek instrument, (4) realistis, yakni berdasarkan kenyataan sebenarnya, (5) antisipatif, yakni mampu menghadapi berbagai permasalahan yang mungkin muncul, (6) konstruktif, atau mengembangkan kreativitas dan inovasi guru dalam pengembangan proses pembelajaran, (7) kooperatif, berarti kerja sama yang baik antara supervisor dan guru untuk pengembangan pembelajaran, (8) kekeluargaan, atau sikap saling mengayomi dalam mengembangkan pembelajaran, (9) demokratis, yaitu supervisor tidak boleh mendominasi pelaksanaan supervisi akademik, (10) aktif, yaitu partisipasi aktif dari guru dan supervisor, (11) humanis, yakni kemampuan menciptakan hubungan kemanusiaan yang harmonis, terbuka, dan transparan, (12) berkesinambungan (supervisi akademik dilaksanakan secara teratur dan berkelanjutan oleh kepala sekolah), 


\section{Volume : 5 \\ Nomor : 4 \\ Bulan : November \\ Tahun : 2019

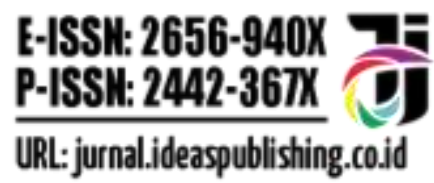

(13) terpadu, yakni saling sinkron dengan program pendidikan, (14) komprehensif, atau memenuhi ketiga tujuan supervisi akademik yang telah disebutkan (Dodd, 1972).

\section{Dimensi-Dimensi Subtansi Supervisi Akademik}

Dimensi-dimensi substansi supervisi akademik adalah (1) kompetensi kepribadian, (2) kompetensi pedagogic, (3) kompetensi professional, (4) kompetensi sosial. Seringkali beberapa kepala sekolah hanya datang dengan membawa instrumen pengukuran kinerja ketika supervisi akademik berlangsung. Kepala sekolah tersebut hanya melakukan pengukuran terhadap kinerja guru yang sementara mengajar dan seusai pembelajaran berakhir. Ia mengganggap tugasnya juga telah selesai dan memandang bahwa supervisi akademik sama dengan pengukuran kinerja guru selama proses pembelajaran.

Perilaku supervisi akademik yang dibahas di atas adalah salah satu contoh yang tidak baik. Supervisi akademik seperti itu hanya akan berkontribusi sangat sedikit atau bahkan tidak memberikan pengaruh signifikan terhadap tujuan dan fungsi supervisi akademik, yaitu peningkatan mutu guru dalam mengelola proses pembelajaran.

Supervisi akademik bukan semata-mata penilaian kinerja guru. Terlebih jika tujuan utama penilaiannya hanya dalam ruang lingkup yang sempit yaitu hanya kualitas keberadaan guru dalam memenuhi kepentingan akreditasi guru yang dinilai. Hal tersebut sangat berlawanan dengan konsep supervisi akademik.

Secara konseptual, supervisi akademik merupakan rangkaian kegiatan membantu guru mengembangkan kemampuan pengelolaan proses pembelajaran untuk mencapai suatu tujuan pembelajaran. Dengan kata lain, esensi supervisi akademik bukanlah penilaian cara guru mengelola proses pembelajaran, melainkan upaya membantu guru dalam mengembangkan profesionalismenya. Walaupun begitu, supervisi akademik sangat erat kaitannya dengan penilaian unjuk kerja guru dalam mengelola pembelajaran.

\section{Perencanaan Program Supervisi Akademik}

Merencanakan supervisi akademik merupakan salah satu tugas kepala sekolah. Ia dituntut agar mampu merancang rencana program supervisi akademik agar dapat melaksanakan tugas sebaik mungkin. 


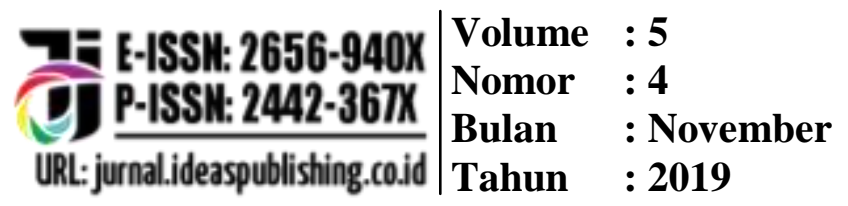

Konsep perencanaan program supervisi akademik dalam merancang perencanaan program supervisi akademik meliputi penyusunan dokumen perencanaan pelaksanaan dan pemantauan sebagaimana tujuan proses supervisi akademik.

1. Manfaat perencanaan program supervisi akademik, yaitu (1) memberi pedoman pelaksanaan dan pengawasan akademik, (2) menyamakan persepsi seluruh elemen sekolah mengenai program supervisi akademik, (3) menjamin penghematan serta efektivitas penggunaan sumber daya sekolah (tenaga, waktu, dan biaya).

2. Prinsip-prinsip perencanaan program supervisi akademik, yaitu (1) objektif (data yang disajikan apa adanya), (2) bertanggung jawab, (3) berkelanjutan, (4) berlandaskan standar nasional pendidikan, dan (5) berlandaskan kebutuhan dan kondisi sekolah/madrasah.

Ruang lingkup perencanaan supervisi akademik, yaitu (1) implementasi KTSP, (2) persiapan, pelaksanaan, serta penilaian pembelajaran oleh guru, (3) pencapaian standar kompetensi lulusan, standar proses, standar isi, dan peraturan implementasi, serta (4) peningkatan mutu pembelajaran melalui: (a) model kegiatan pembelajaran berdasarkan standar proses, (b) proses pembelajaran dalam rangka peningkatkan kemampuan peserta didik menjadi SDM berkualitas dan memiliki naluri kewirausahaan, (c) peserta didik mampu membentuk karakter dan memiliki pola pikir yang baik sehingga mampu mengembangkan kemampuan mereka sebagai manusia yang mandiri, kreatif, dan memiliki wawasan kebangsaan, (d) keterlibatan aktif peserta didik dalam proses belajar yang dilaksanakan secara sungguh-sungguh untuk memahami konsep yang tidak terbatas pada materi yang diajarkan guru, (e) bertanggung jawab terhadap mutu perencanaan kegiatan pembelajaran pada setiap mata pelajaran yang diampu guru.

\section{Simpulan}

Secara konseptual, supervisi akademik merupakan rangkaian kegiatan yang bertujuan membantu guru mengembangkan kemampuan pengelolaan pembelajaran dan profesionalisme guru untuk mencapai tujuan pembelajaran. Esensi supervisi akademik bukan sekadar penilaian kinerja guru dalam mengelola pembelajaran. Dengan kata lain, 


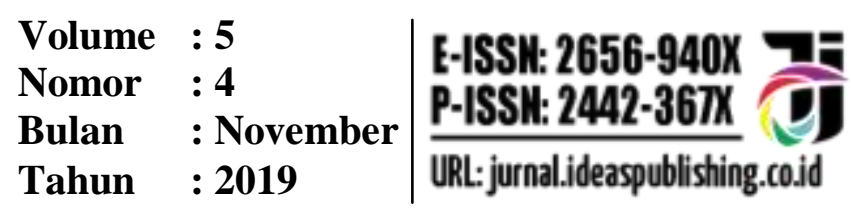

supervisi akademik sangat berkaitan erat dengan penilaian performa guru dalam mengelola pembelajaran.

Perencanaan program supervisi akademik, sebagai tugas kepala sekolah dalam merencanakan supervisi akademik. Kepala sekolah dituntut untuk memiliki kompetensi merancang rencana program supervisi akademik agar mampu melaksanakan tugasnya dengan baik. Hal ini dilakukan dengan penyusunan dokumen perencanaan pelaksanaan dan pemantauan untuk mewujudkan tujuan supervisi akademik seperti yang telah disebutkan.

\section{Daftar Pustaka}

Suraiya dkk. (2016). "Pelaksanaan Supervisi Akademik oleh Kepala Sekolah dalam Meningkatkan Kompetensi Profesional Guru”. Jurnal Administrasi Pendidikan, (4). 1. http://www.jurnal.unsyiah.ac.id/ JAP/article/view/2616. Diakses pada tanggal 19 Mei 2019.

Glickman, C.D., Gordon, S.P., dan Ross-Gordon, J.M. (2007). Supervisionand Instructional Leadership A Development Approach. Seventh Edition. Boston: Perason.

Daresh. (1989). Supervison as Approactive Process. New Jersey: Longman.

Sergiovanni. (1987). Educational Governance and Administration. New Jersey: Prentice Hall Inc.

Dodd, W.A. (1972). Primary School Inspection in New Countries. London: Oxford University Press. 


$\underset{\text { URL:jurnalideaspublishing.co.jd }}{\text { DT E-ISSH: 2656-940X }} \begin{array}{ll}\text { Volume } & : 5 \\ \text { Nomor } & : 4 \\ \text { Bulan } & : \text { November } \\ \text { Tahun } & : 2019\end{array}$

